\title{
A conversation with Andrew Benson: reflections on the discovery of the Calvin-Benson cycle
}

\author{
Bob B. Buchanan · Joshua H. Wong
}

Received: 30 November 2012/ Accepted: 6 December 2012/Published online: 27 December 2012

(C) Springer Science+Business Media Dordrecht 2012

\begin{abstract}
On June 26-27, 2012, one of us (BBB) made a video based on an interview conducted with Andrew A. Benson, Professor Emeritus, Scripps Institution of Oceanography, University of California, San Diego, CA, USA. The video was first shown in a seminar presented by BBB on July 27, 2012 at the Calvin Laboratory, University of California, Berkeley, to mark the departure of the Energy Biosciences Institute to a new building. Here we record the conversation taking place during the interview. The Brancraft Library on the Berkeley campus will house the video's transcript in its oral histories collection, and the video will be housed in its motion picture collection. The video and the transcript have also been posted on You Tube (http://youtu.be/GfQQJ2vR_xE).
\end{abstract}

Keywords Andrew Benson · Melvin Calvin · CalvinBenson Cycle · CO2 fixation · 3-phosphoglyceric acid . Ribulose-1,5-bisphosphate

\section{Prologue}

The interview presents an overview of Benson's undergraduate and graduate education, his experiences as a

Dedicated to Govindjee to commemorate his 80th birthday. Govindjee played a primary role in convincing Andrew Benson to speak out about certain of his experiences described in the video, especially events taking place just prior to his departure from Berkeley [Benson AA (2010) Last days in the old radiation laboratory (ORL), Berkeley, California, 1954. Photosynth Res. 105:209-212].

B. B. Buchanan $(\bowtie) \cdot$ J. H. Wong

Department of Plant and Microbial Biology, University of California, 111 Koshland Hall, Berkeley, CA 94720, USA

e-mail: view@berkeley.edu young Ph.D. and the eight years he spent as a researcher in Melvin Calvin's laboratory when the photosynthetic carbon cycle was worked out. It becomes apparent that Benson's contributions to elucidating the cycle are manifold. They include bringing expertise in carbohydrate chemistry and experience with radioactive carbon to Calvin's research group; introduction of experimental approaches such as the "lollipop," radioautography and procedures for degrading intermediates of the cycle; identification of 3-phosphoglyceric acid as the first stable product formed in short exposure experiments with ${ }^{14} \mathrm{CO}_{2}$ (with Calvin); and discovery of ribulose-1,5-bisphosphate, the elusive intermediate that enabled the group to formulate the cycle-a concept that Calvin had long championed as the mechanism of $\mathrm{CO}_{2}$ fixation in photosynthesis. Benson describes first-hand how the experiments were carried out and what life in the Calvin laboratory was like. The interview also gives insight into the character of the principals involved. The interview is followed by an Epilogue that describes previously undisclosed details surrounding a manuscript Benson completed just before leaving Berkeley for Penn State. The video and the transcript have been posted on You Tube (http://youtu.be/GfQQJ2vR_xE).

\section{BEGINNING OF VIDEO}

Buchanan: I'm at the Scripps Institution of Oceanography in La Jolla, with Andrew Benson, where he is an emeritus professor of biology. We are in an office Dr. Benson has occupied since he arrived at Scripps in 1962. In today's interview, Andy, I would like to discuss your career, focusing on research that led to the discovery of the Calvin-Benson cycle in photosynthesis, a pathway essential to the growth of all plants. This work was done in 
collaboration with the late Melvin Calvin in the Chemistry Department at Berkeley. Andy, for today's purposes, we will start early in your life with your arrival as a freshman at Berkeley. Andy, you arrived in Berkeley in 1935 as a young chemistry major. Why did chemistry interest you?

Benson: Because in high school I had an excellent-a very interesting chemistry teacher. He had been on the football team of Stanford University. And he was a big guy. And everyone was afraid of him. (laughs). But he had-did some tricks that really fooled everybody.

\section{Student days}

Buchanan: So that was one of the attractions. Well, after you arrived in Berkeley, your father took you to meet Wendell Latimer, a well-known chemist who was chairman of the Chemistry Department. What were your first impressions of the campus after you arrived as a youth, fresh from central California?

Benson: Well, it was full of people (laughs) and they all knew where they were going.

Buchanan: (laughs)

Benson: And I was only going to hopefully find the Chemistry Department.

Buchanan: Well, after completing your Bachelor's degree, you continued as a chemistry graduate student at Cal Tech, where you worked with Carl Niemann, one of the nation's most distinguished chemists. What was Professor Niemann's specialty?

Benson: He was a specialist in carbohydrate chemistry, anything involving sugar molecules and plastics and everything. He-his lectures, over three years, were brilliant. And he was a well known — chairman of the chemistry — chemists of the National Academy of Sciences.

\section{As a young Ph.D. in Berkeley}

Buchanan: This training provided excellent preparation for the research you were to carry out following your return to Berkeley as a young Ph.D. in 1942. At that time, there was great activity in chemistry at Berkeley. What was the Chemistry Department like in 1942?

Benson: I was in charge of several sections of the teaching groups in chemistry.
Buchanan: So this was your role as a faculty member.

Benson: Yeah. And the students in those two groups that I managed were absolutely at the top of the students, as far as their test scores went. And they were-later they were the key leaders of chemistry in the United States.

Buchanan: I'd now like to turn to the early isotope studies you carried out in Berkeley. We'll start with carbon-11, the radioactive form of carbon that Sam Ruben and Martin Kamen used in their early photosynthesis experiments. Carbon-11 has a half-life of only $20 \mathrm{~min}$, a short time to do an experiment. What were Ruben and Kamen able to accomplish in their carbon-11 experiments in such a short time?

Benson: Oh, Sam Ruben published about 30 papers, and in collaboration with all kinds of microbiologists, studied different-different reactions. But they made no progress with respect to the absorption and conversion of carbon dioxide to carbohydrates.

Buchanan: In photosynthesis.

Benson: Yeah.

Buchanan: So his contributions were mainly with bacteria.

Benson: Yeah. With many people, in different laboratories.

Buchanan: Did he work with Barker?

Benson: Yes.

Buchanan: And Hassid?

Benson: Yeah.

Buchanan: —on the campus. So these were early-

Benson: Hassid was a good friend of mine.

\section{Early photosynthesis experiments}

Buchanan: So these were early contributions. During this period, Ruben and Kamen discovered carbon14 , an isotope with a half-life of more than 5,000 years. Ernest Lawrence, Director of the Radiation Laboratory, saw the great potential of carbon-14, and asked Calvin to continue the work of Ruben and Kamen and apply the isotope in studies of photosynthesis. You joined his research group in 1946. Calvin recognized your experience with carbon-14, but did he appreciate your expertise in carbohydrate chemistry that you acquired at Cal Tech?

Benson: No. He didn't know very much about carbohydrate chemistry. 
Buchanan: Let's now discuss the photosynthesis experiments with Carbon-14 $\mathrm{O}_{2}$ that you carried out in Calvin's laboratory. By the way, Andy, you may be the only living person who has worked with the four carbon isotopes, C-11, C-12, C-13, and C-14. Did this broad experience help you in your photosynthesis work at Berkeley?

Benson: No, I didn't worry about that until years later, (laughs) when I wrote an article about it. But that just doesn't-no great invention or anything.

Buchanan: It probably didn't occur to you (laughs) until sometime later, actually.

Benson: Yeah.

Buchanan: Can you describe how the $\mathrm{C}^{14} \mathrm{O}_{2}$ photosynthesis experiments were carried out, starting with the type of cells that were used?

Benson: Well, one of the members of the group was an-was an expert at culturing algae, so Vicky Lynch took care of that side of the problem. Easy to measure the volume of algae. It would be difficult with leaves of plants and things like that, but with algae you spin them down in a centrifuge and measure their-their dimensions and you know how much you got. And at first, I was extracting the radioactive products with toluene andand ethyl alcohol, which was pretty stupiduntil Al Bassham started using methyl alcohol. Because this was perfect. Methyl alcohol destroys a cell membrane and everything falls out and it's easy to have a solution.

Buchanan: So that-methanol turned out to be an excellent way to stop reactions.

Benson: Yes.

Buchanan: Actually, one of the advantages of the algae is that you can pipette them.

Benson: Yeah.

\section{Discovery of 3-phosphoglyceric acid}

Buchanan: You can manipulate them very easily. So one of the early experiments you did after your return to Berkeley was to look for the first stable, labeled product in the $\mathrm{C}^{14} \mathrm{O}_{2}$ photosynthesis experiments. You were successful in that endeavor. What is that-what is the name of that product?

Benson: Three-phosphoglyceric acid.
Buchanan: 3-Phosphoglyceric acid. And who-who discovered that product?

Benson: I and Melvin really-I separated the products on an ion-exchange column. And there were two peaks, indicating that there were twotwo acidic groups. And one was a carboxyl of 3-phosphoglycerate and the other was the phosphate.

Buchanan: How did you know that this was the earliest stable product? Did you do a short exposure experiment?

Benson: Short exposure to radioactive $\mathrm{CO}_{2}$.

Buchanan: And this was the first product you saw.

Benson: Yeah.

Buchanan: And one of the new aspects was the use of the ion-exchange column to identify this radioactive product.

Benson: Yeah.

Buchanan: And then, once that product was identified, once 3-phosphoglyceric acid was identified, that influenced subsequent research in the laboratory to- - to elucidate the path of carbon dioxide in photosynthesis. The early work was started with Warburg vessels that were common at the time. But the Warburg vessel evolved to this modified form.

Benson: $\quad$ A Warburg vessel was more like a little flask. So I had-made a flat one, so it would get a lot of light on them. And-and it will work much better.

Buchanan: So this would be a modified Warburg vessel. But the real ingenuity came with the development of the lollipop. Could you describe that?

Benson: If you want to put algae spread out over a certain area, you just flatten the thing. Instead of shaking that way, it's-you can shake it this way, by bubbling air through it or nitrogen or whatever you want.

Buchanan: How was the lollipop illuminated?

Benson: From both sides.

Buchanan: From both sides.

Benson: $\quad$ Yeah. Either by-with fluorescent lights or by shooting through a glass through watercontained-heat absorbing glass. And the water took away the heat out of the glass, to keep it from cracking.

Buchanan: I think the approach was to expose cells to $\mathrm{C}^{14} \mathrm{O}_{2}$ for short experiments and then follow the carbon as it progressed 
Buchanan: -with time. Could you show how you removed the samples from the lollipop?

Benson: Well, you turn the stopcock to collect the algae.

Buchanan: Who designed the lollipop?

Benson: I did.

Buchanan: You did. But then, in this case, the-you open the stopcock and, after a certain period of time, the contents were transferred to hot methanol.

Benson: Yeah.

Buchanan: And that stopped the reaction.

Benson: Instantly.

\section{Separation of ${ }^{14} \mathrm{C}$-products}

Buchanan: Instantly. And then how did you identify the products that had been formed?

Benson: Well, you separate them by filter paper chromatography.

Buchanan: How did you use paper chromatography to separate the products? Could you describe that? Here's a paper chromatogram. What did you do to separate the compounds?

Benson: Well, you put all the products at the originlet's say the origin is here-and then develop it in this direction first, by putting it in a troughdipped in phenol saturated with water. And it goes through the paper. And then you turn it-

Buchanan: One of the solvents used in the second dimension was butanol propionic acid water. Did you develop that solvent?

Benson: Oh, yeah.

Buchanan: Yes. So the combination of phenol water and butanol propionic acid water turned out to be very effective. And it was used subsequently by laboratories around the world.

Benson: Fortunately, I did an experiment with the compounds moving in the paper. And, of course, the paper absorbs the water but not the other organic compounds. So as it moves, the solvent characteristics kept changing. So that greatly enhanced the function of the second solvent.

Buchanan: Who advised you to use two-dimensional paper chromatography?

Benson: Oh, it was invented in England. But they had stupid solvents that were absolutely poisonous. And the physicists were upstairs, who were-using a drier for the paper chromatograms. They-they were getting sick. And that just means a change of solvents, so they could tolerate them better.
Buchanan: So the originators of the technique were Martin and Synge?

Benson: Yeah.

Buchanan: And at Berkeley, you were in the same building with the physicists.

Benson: Yeah.

Buchanan: Was this the old Radiation Laboratory?

Benson: Yeah.

Benson: It was all physicists. When-when we moved in, they had uranium all over the floor, which was a little bit radioactive. So I-I got some cheap linoleum and placed it on top of it. And that blocked it off. And we-

Benson: - -we didn't have any chemical hoods in the laboratory, where you could work with things and the air would be exhausted out the top. We just had big windows. And we opened the windows and hoped for the best. And all the amino acids, like alanine, glutamic acid, they traveled different distances.

Buchanan: And so the 3-phosphoglycerate was separated from-

Benson: It goes-

Buchanan: - the sugar phosphates

Benson: - -would go up here.

Buchanan: So you probably learned to recognize that as a very bright spot-

Benson: Yeah.

Buchanan: —in short-exposure-

Benson: Very dark spot.

Buchanan: -samples. And then how did you locate the compounds that were labeled in the photosynthesis experiments?

Benson: We did-by Geiger counters, just scan them.

Buchanan: So you got the major ones that way. But the minor ones, you had to go to the technique of radioautography.

Benson: Well, yeah. You put-leave on film a long time and the minor ones would show.

Buchanan: So who advised you to combine the paper chromatography with the radioautography?

Benson: I did.

Buchanan: This is a radioautogram made from an experiment that Andy did after he left Calvin's laboratory. But it demonstrates the technique beautifully. And you see the radioactive compounds are fully separated. And after they can be seen, they're cut out, then can be used to further localize the activity.

Benson: $\quad$ You cut them out and put them in little things with a paper point here and hang them in water. And it washes all the stuff out thatAnd then you put it back on another 
chromatogram, and you see what's all in that particular spot.

\section{Localization of ${ }^{14}$ carbon label}

Buchanan: Once you know the products, you can cut them out, add unlabeled carrier and degrade the compound and see where the label is. And then in some cases you co-crystallized the known compound with the radioactive compound. Let's now turn to the localization of the radioactive carbon in the individual compounds. Had techniques been developed for the stepwise chemical degradation of these compounds, the intermediates of the carbon cycle?

Benson: There were several ways to degrade or split apart the molecule. And I figured out how to do that. And measure part of seven carbon of sugar, we know what reagent splits it where. And so we measure that radioactivity.

Buchanan: So this would be the intermediate, sedoheptulose phosphate.

Benson: Yeah.

Buchanan: So had the techniques been developed for degrading that? Or was that done by someone else?

Benson: I did it.

Buchanan: So you developed for the sedoheptulose, which was a-

Benson: Yeah. Yeah.

Buchanan: —an interesting sugar phosphate in-that was identified as the member of the cycle.

Benson: $\quad \mathrm{Al}$ Bassham did a very good job of doing it. He was a graduate student in our department. He was getting his $\mathrm{PhD}$.

Buchanan: So the sedoheptulose phosphate intermediate, that work was done with you and Al Bassham, the degradation of that sugar phosphate-

Benson: Yeah.

Buchanan: - Which was a pivotal-

Benson: Of the sugar, not the sugar phosphate. We took the phosphate off.

Buchanan: How did you proceed once you had identified the sugar phosphate on the chromatogram, how did you proceed to degrade the compound to show where the label was?

Benson: We removed the phosphate and then oxidized it with periodate or lead tetraacetate. And it cut the molecule apart at predictable places.

Buchanan: How did you remove the phosphate?

Benson: By a phosphatase.
Buchanan: I read that you used Polidase-

Benson: Yeah.

Buchanan: -and treated the sugar phosphates with Polidase. And then once the phosphate was removed, you could degrade-

Benson: Group by group.

\section{Discovery of ribulose-1,5-bisphosphate}

Buchanan: Group by group. And this enabled you to show where the label had moved from the beginning. Andy, one of your great achievements was the discovery of ribulose-1,5diphosphate. This finding provided the missing link in the cycle. It was possible to put many years of experiments together and to formulate the Calvin-Benson cycle as we know it. How did you discover this metabolite that was new to biology?

Benson: I had studied carbohydrate chemistry with Carl Niemann for getting my $\mathrm{PhD}$ at $\mathrm{Cal}$ Tech. I knew how to take things apart and identify the pieces.

Buchanan: What conditions did you use to accumulate the sugar phosphate in the alga?

Benson: Oh. The thing is to just don't give them any carbon dioxide. And they keep making the compound, looking for some carbon dioxide to react with.

Buchanan: So this was the brilliant introduction, to deprive the cells of carbon dioxide, so the acceptor for the carbon dioxide accumulated in sufficient amounts to identify it.

Benson: Yeah.

Buchanan: And then you followed the usual procedure that you worked out. Making such a discovery's rare. Can you let young scientists know how you felt once you realized the significance of this result?

Benson: Didn't bother me one bit. Because I just didI wasn't surprised.

Buchanan: So you moved on.

Benson: Yeah. (laughs) There was plenty else to do.

Buchanan: Do you consider this your most important discovery?

Benson: $\quad$ Oh, I-I think so, finding ribulose diphosphate.

Buchanan: For those people who may not know, ribulose diphosphate, the name was later changed to ribulose-1,5-bisphosphate. I learned the ribulose 1,5-diphosphate. But now textbooks often call it 1,5-bisphosphate.

Benson: That means the phosphate is on both ends. 
Buchanan: This important discovery of ribulose 1,5diphosphate or -bisphosphate, did Calvin appreciate your success?

Benson: He didn't realize what it was for a while.

Buchanan: You published this work as a short paper, in which you were the sole author. Calvin's name was on almost all papers from his research group but it was not on this paper. Why not?

Benson: Because he-he had a heart attack and he was, the next year or more in Norway recovering.

Buchanan: So he had the heart attack in Berkeley and went to Norway.

Benson: Because his wife's mother was Norwegian. And they went to live in Norway.

Buchanan: But while he was away, you finalized this ribulose diphosphate work and wrote the paper and sent it off.

Benson: Yeah.

Buchanan: But I assume you sent the paper to him also.

Benson: Yeah.

Buchanan: But he chose not to put his name on it. Calvin certainly knew about the paper but, as far as I know, he rarely cited it. Do you understand that?

Benson: No. But I'm not surprised.

\section{$\mathrm{CO}_{2}$ is fixed via a cycle}

Buchanan: Let's now discuss the development of the cycle. I'd like to know your thoughts about how the concept of the photosynthetic carbon cycle was developed.

Benson: Well, Calvin was a "cycle maniac." $\mathrm{He}-$ everything — every reaction that he studied, he tried to make a cycle out of it.

Buchanan: You made the point that Calvin was, one might say, obsessed with cycles. What was the basis for this obsession?

Benson: (laughs) I never worried about it.

Buchanan: (laughs)

Benson: But that's what he-He thought there should be a cycle, so the product would be reconvertible to the acceptor again.

Buchanan: So that turned out to be correct.

Benson: Yeah.

Buchanan: It was a cycle. Because at the time, for many years, it was thought that carbon dioxide was converted directly to a reduced form of carbon-

Benson: Yeah.
Buchanan: Warburg's hypothesis.

Benson: Yeah.

Buchanan: But the cycle showed that this was not correct, by any means. So Calvin did-a main contribution was the concept of the cycle.

Benson: So anytime you've got a compound that reacts with carbon dioxide, enzymatically, and it splits in half to make two $\mathrm{C}-3$ pieceswhich are exactly the same as the first product that you observe giving a plant carbon dioxide.

Buchanan: And so this product was 3-phosphoglyceric acid. And it had been observed for many years. But it was not known how it was formed until you found ribulose 1,5-diphosphate.

Benson: Yeah, yeah. That's right.

Buchanan: Calvin didn't recognize that the ribulose-1, 5-diphosphate made the whole cycle.

Benson: No, I don't think he realized that for a long time.

Buchanan: Even though-I think you said-he had "cyclitis."

Benson: Yeah.

Buchanan: He somehow didn't recognize this. Which members of the photosynthesis research group at Berkeley made the most important contributions in elucidating the carbon cycle besides you and Calvin?

Benson: $\quad \mathrm{Oh}, \mathrm{Al}$ Bassham, by a long shot. He wrote a great many papers on the various reactions and interactions which occurred. And they were good papers but not novel.

\section{The thioctic acid theory}

Buchanan: Not novel. The next area is a very interesting one, I think, the thioctic acid theory. At one point, Calvin visualized that a recently discovered coenzyme, thioctic acid or lipoic acid, could explain photosynthesis. Thioctic acid in its oxidized state has a disulfide bond.

\section{Benson: Yeah.}

Buchanan: Calvin predicted that, in the splitting of water in photosynthesis, hydrogen would be used to reduce one sulfur atom and the other sulfur atom would be oxidized to the $-\mathrm{SOH}$ state.

Benson: Yes, that's right.

Buchanan: And then the reduced sulfur atom would give rise to reduced pyridine nucleotides and the oxidized sulfur atom would give rise to oxygen. But many people in his laboratory tried to prove this theory. I think Clint Fuller 
was one of the ones. But you worked on it, as well. What was your conclusion after-?

Benson: My conclusion was that it's impossible. Because I added radioactive sulfur to the system and it gave one product, which we called a sulfolipid.

Buchanan: But so this influenced your later work in which you discovered sulfur lipids.

Benson: Yeah.

Buchanan: But Calvin was really enamored with the theory and spoke about it widely, in his usual persuasive style, I assume. For example, he gave the keynote address at the Thioctic Acid Conference in Naples, Italy, in 1955. Was his theory recognized by the scientific community?

Benson: $\quad$ Yeah, I think, for a while

\section{Leaving Berkeley}

Buchanan: Now let's go to the time you left Berkeley. You left Calvin's laboratory after the evidence for formulating the photosynthetic carbon cycle was complete. Under what conditions did you leave Berkeley?

Benson: He said it was time to get out of here, "time to go," as he said.

Buchanan: So Calvin released you.

Benson: Released? I wasn't getting anything for it.

Buchanan: So, would you use the word "fired?"

Benson: Yeah.

Buchanan: Did you have a job waiting for you?

Benson: No! So I-I called my brother-in-law at Penn State. And he called the head of the department—say, "Sure! Have him come over. We'll do everything for him." So there I was. So I had very good graduate students at Penn State.

Buchanan: And what did you accomplish at Penn State? What was your major work?

Benson: Well, I discovered phosphatidylglycerol for one thing.

Buchanan: In plants.

Benson: Yeah.

Buchanan: And the sulfur lipids.

Benson: And sulfonic acid. Nobody ever heard of a sulfonic acid in natural compounds. But I invented that.

\section{Calvin's writing and management styles}

Buchanan: So these were pioneering contributions as well. You mentioned to me once that Calvin had a remarkable memory.
Benson: Yeah, he did. When we were publishing a paper, he would march around the table and just dictate the paper to Marilyn who was an excellent secretary.

Buchanan: Calvin was known for his organization and management skills. Were these skills apparent in the way he ran his research group?

Benson: Yeah-wasn't apparent but actually it was the case. And the real manager of Melvin Calvin was his secretary, who was brilliant. And she kept him communicating with chemists all over the world. Calvin would start lecturing as if he didn't know anything. And then he would increase in volume and-and everything, where he explained everything. (laughs) And that was a masterful job.

Buchanan: Did you and Calvin remain on friendly terms after you left his group?

Benson: We never were on unfriendly terms but would-I just sort of put up with it.

\section{A typical day in the Calvin Laboratory}

Buchanan: Now let's talk about life in Calvin's laboratory on a day-to-day basis. What was a typical day in the laboratory like?

Benson: Well, at 8:00, there was Melvin Calvin in his business suit, with "What's new?" Because we'd been working all night, running chromatograms and treating them. Usually we didn't tell him everything. Because sometimes we didn't have much news and then we could tell him.

Buchanan: So you would save something-

Benson: Yeah.

Buchanan: - in the bank, so to speak. What took place in the Friday morning group meetings?

Benson: Oh, they were pretty effective. But the interactions between the individuals didn't amount to too much. That's my opinion.

Buchanan: What role did Marilyn Taylor, Calvin's secretary for more than 50 years, play in the workings of the laboratory?

Benson: Oh, she was fantastic! She organized his travel and everything. She wrote all the letters about where he's going and so forth.

\section{Major lessons}

Buchanan: What was the most important lesson you learned from working with Calvin? 
Benson: To go someplace else. Because I knew about so many other things and an awful lot more about carbohydrate chemistry than he knew. So, I figured I could deal with any kind of problem.

Buchanan: In hindsight, was the time you spent with Calvin helpful in your research after you left his laboratory?

Benson: Was it helpful after I left? Not especially. But there was about 20 papers published by Calvin and Benson or Benson and Calvin. So.

\section{Bioenergy}

Buchanan: A very productive time. I'd now like to move to certain events that took place after you left Berkeley. Quite some time after your departure, Calvin started work on what is now known as biofuels or bioenergy. What is your impression of his work in this area?

Benson: I thought it was all nonsense, so I didn't bother with it. He went around the world looking at plants that grew real fast. Any plant grows real fast in the tropics.

Buchanan: But you thought that it didn't lead to anything lasting.

Benson: No.

\section{Recognition}

Buchanan: As is sometimes the case with important research findings, contributions by key individuals are not uniformly recognized. Many believe this was true of the photosynthesis carbon work for which Calvin received a Nobel Prize in 1961 and you were overlooked. Could you tell us about how you felt when you learned that Calvin received the prize?

Benson: I-I didn't worry about it.

Buchanan: So, it didn't bother you.

Benson: No.

Buchanan: And you had other problems to work on.

Benson: Yeah. I visited-visited him several times after that, with Gerard Mihaud and several other people. And we got along just fine, but not terrific. He published a book, an autobiography, Following the Trail of Light, which is a fantastic - a beautiful title for what it was about. It makes the whole volume about him getting a Nobel Prize, no mention of Benson at all in that book. And he didn't have to do that. He could have done it right. And finally, one of his last publications he mentioned-
Dr. Benson and some graduate students were involved-but just briefly mentioned.

\section{Longevity}

Buchanan: So you will turn 95 in September. Do you believe this attitude of being able to take the big picture and move on in a situation such as the Nobel Prize have contributed to your longevity?

Benson: $\quad$ No. I just eat cactus every morning.

Buchanan: This brings to mind a quotation from John Greenleaf Whittier's "Maud Muller," that he wrote in the 1850s. "Of all sad words of tongue, and pen, the saddest are these: It might have been!" Andy, you had the wherewithal to move on with your life and face new problems. I think this is a lesson for all of us. Thank you, Andy, for the insights you have given us into topics that will be of broad interest to many people and I believe will benefit from those for years to come.

\section{Epilogue}

In his closing months in Berkeley, Benson worked feverishly with Jacques Mayaudon, a Belgian postdoc, in identifying S. Wildman's Fraction I protein as Rubisco. Benson left the manuscript with Calvin before departing for Penn State in 1954. Calvin presented the results in 1955 at the International Congress of Biochemistry, mentioning Mayaudon but not Benson (Cavin 1955). The critical findings were published in 1957 with Mayaudon as sole author (1957). It is not clear who submitted the Mayaudon manuscript. Benson became aware of these publications after Calvin's death more than 40 years later.

\section{END OF VIDEO}

Acknowledgments A number of colleagues helped make this video possible. We wish to acknowledge our science advisers: Roland Douce (Grenoble), Hartmut Lichtenthaler (Karlruhe), George Lorimer (College Park) and Roger Summons (Cambridge); technical adviser, Marie Felde (UC Berkeley); video production personnel, Mike Fausner and Matt Hale (Creative Services and Publications, UC San Diego); and the sponsor of the video, Energy Biosciences Institute (UC Berkeley). We also thank H. Lichthenthaler for comments on the manuscript.

\section{References}

Calvin M (1955) The photosynthetic carbon cycle. In Liébecq C (ed) Proceedings of the third international congress of biochemistry, Brussels, Academic press, New York, pp 211-225

Mayaudon J (1957) Study of association between the main nucleoprotein of green leaves and carboxydismutase. Enzymologia $18: 343-354$ 